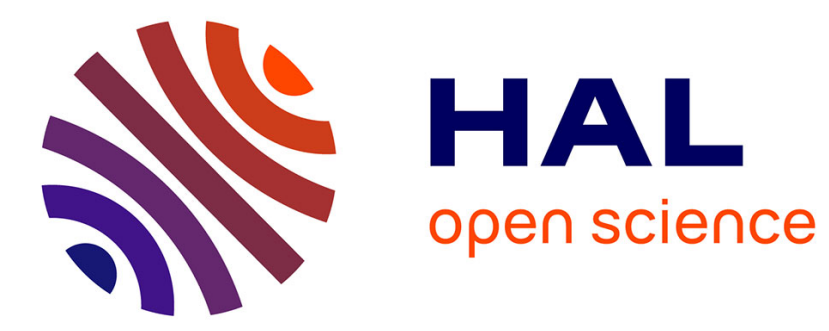

\title{
Efferent controls in crustacean mechanoreceptors
}

Daniel Cattaert, Morgane Le Bon, Didier Le Ray

\section{To cite this version:}

Daniel Cattaert, Morgane Le Bon, Didier Le Ray. Efferent controls in crustacean mechanoreceptors. Microscopy Research and Technique, 2002, 58 (4), pp.312-324. 10.1002/jemt.10139 . hal-02347033

\section{HAL Id: hal-02347033 \\ https://hal.science/hal-02347033}

Submitted on 7 Nov 2019

HAL is a multi-disciplinary open access archive for the deposit and dissemination of scientific research documents, whether they are published or not. The documents may come from teaching and research institutions in France or abroad, or from public or private research centers.
L'archive ouverte pluridisciplinaire HAL, est destinée au dépôt et à la diffusion de documents scientifiques de niveau recherche, publiés ou non, émanant des établissements d'enseignement et de recherche français ou étrangers, des laboratoires publics ou privés. 


\title{
Efferent controls in crustacean mechanoreceptors
}

\author{
Daniel CATTAERT, Morgane LE BON and Didier LE RAY
}

Laboratoire de Neurobiologie des Réseaux, LNR, UMR 5816, CNRS - Université de Bordeaux 1, Biologie Animale, Bat B2, Avenue des Facultés, 33405 Talence, France

\author{
Author for Correspondence: D. Cattaert \\ Laboratoire de Neurobiologie des Réseaux, LNR, \\ UMR 5816, CNRS - Université de Bordeaux 1, \\ Biologie Animale, Bat B2, Avenue des Facultés, \\ 33405 Talence, France \\ Tel: +33(0) 557962567 \\ Fax: +33 (0) 557962561 \\ email: d.cattaert@lnr.u-bordeaux.fr
}

Running Title: Efferent controls in crustacean mechanoreceptors

Key Words: crustacea, primary afferent, proprioception, presynaptic inhibition, neuromodulation, plasticity. 


\section{ABSTRACT}

Since the 60 's, it is admitted that central neural networks can elaborate motor patterns in the absence of any sensory feedback. However, sensory and neuromodulatory inputs allow the animal to adapt the motor command to the actual mechanical configuration or changing needs. Many studies in invertebrates and in crustacea in particular have described several mechanisms of sensory-motor integration and have shown that part of this integration was supported by the efferent control of the mechanosensory neurons themselves. In this article, we review the findings that support such an efferent control of mechanosensory neurons in crustacea. Various types of crustacean proprioceptors feeding information about joint movements and strains to central neural networks are considered, together with the evidence of efferent controls exerted on their sensory neurons. These efferent controls comprise (i) the neurohormonal modulation of the coding properties of sensory neurons by bioamines and peptides; (ii) the presynaptic inhibition of sensory neurons by GABA, glutamate and histamine; and (iii) the long-term potentiation of sensory-motor synapses by glutamate. Several of those mechanisms can coexist on the same sensory neuron, and the functional significance of such multiple modulations is discussed. 


\section{INTRODUCTION}

Mechanosensory inputs are involved in a diversity of functions during the production of adaptive motor behaviors (initiation and termination of motor sequences, modulation of movement amplitude and/or movement period). In particular, proprioceptive inputs exert such a powerful control on motor output that many scientists considered for a long time that motor patterns resulted exclusively from chains of reflexes (e.g., Sherrington, 1910). However, after the demonstration by Wilson (1961) in the locust that the motor pattern of flight could be generated in the absence of any sensory feedback, the concept of central pattern generator (CPG) was accepted. Following this former demonstration, many other studies showed that various central neural networks were able to elaborate rhythmic motor patterns when totally isolated from sensory inputs (Selverston, 1985; Kiehn and Kjaerulff, 1998). In parallel with the analysis of those CPGs, the relationship between sensory inputs and CPGs was also studied, and many data support the idea that sensory inputs finely reshape the ongoing motor command. This view is close to the pioneering proposal of Brown (1911) that "the proprioceptive stimuli which are generated by the contraction of muscles play a regulating and not an intrinsic part in the act".

Nevertheless, sensory information is not completely independent from the central activity. As shown in crustacea (Sillar and Skorupski, 1986), insects (Wolf and Burrows, 1995) and vertebrates (Dubuc et al., 1988), mechanosensory neurons are in turn controlled by central neural networks via presynaptic inhibition (Gossard et al., 1989; Gossard, 1996). However, the presynaptic control of sensory afferents may not originate exclusively from central activity. Indeed, the first demonstration of an efferent control of primary afferents was provided by Frank and Fuortes on Ia afferents presynaptically inhibited by other muscle 
primary afferents (Frank and Fuortes, 1957). Nevertheless, because of the unequaled accessibility of the various neuronal elements involved in their reflex loops, arthropods offer exceptional models in which to study efferent controls of primary afferents. Indeed, crustacean preparations provided very early evidences of an efferent control of mechanoreceptors, as for example in the abdominal muscle receptor organ (Eckert, 1961; Kuffler and Eyzaguirre, 1955). In crustacea, most of the data indicating the existence of an efferent control of mechanosensory neurons were provided by electrophysiological analyses, and contrary to insects (Watson, 1992), very few anatomical data are available (Elekes and Florey, 1987a; Elekes and Florey, 1987b; Kirk and Govind, 1990; Lee and Krasne, 1993; Newland et al., 1996).

Although most of the data supporting the efferent control of sensory afferents have been obtained in various sensory structures in different species, several of them may coexist in the same sensory neuron. This was demonstrated for example in the crayfish CBCO, the chordotonal organ that monitors the movements of the second (coxo-basipodite) joint of the legs (Bévengut et al., 1997; Cattaert and Le Ray, 1998; Cattaert et al., 1999; Clarac et al., 2000; El Manira and Clarac, 1994; Le Ray and Cattaert, 1999). Because, in this review, a lot of data will concern the crayfish $\mathrm{CBCO}$, its anatomical organization and its role in movement control will be exposed briefly. Then, the various mechanisms of efferent control described so far on this mechanoreceptor, exerted at the level of either the peripheral sensory organ or the sensory terminals within the central nervous system, will be presented and compared to the efferent control mechanisms described on other crustacean mechanoreceptors.

\section{A - The coxo-basipodite chordotonal organ (CBCO) : a crustacean proprioceptor}


In the crayfish, upward and downward movements of the legs are controlled by a couple of antagonistic muscles, the pair anterior/posterior levator muscles and the depressor muscle, respectively. Those vertical movements are coded by a specific proprioceptor located at the base of each walking leg, across the second (coxo-basipodite) leg joint (Fig. 1A). This mechanoreceptor, the $\mathrm{CBCO}$, is composed of 40 cells embedded in an elastic strand that runs between the anterior and posterior levator muscles. Because of its position within the joint, the CBCO strand is stretched when the leg moves downward and released when the leg moves upward. The implication of this chordotonal organ in motor control was mostly analyzed in an in vitro preparation (Fig. 1B). Within the elastic strand of the $\mathrm{CBCO}$ (Fig. 2A), the sensory cells are grouped in pairs in complex structures called scolopidia, with their dendrites embedded in the conjunctive tissue of the strand. The sensory neuron codes either the levation (CBCO release) or the depression ( $\mathrm{CBCO}$ stretch) of the leg. The axons of the $\mathrm{CBCO}$ sensory neurons project in the lateral neuropile of the thoracic hemiganglion that controls the leg (see inset in Fig. 2B), where they release acetylcholine on their target cells.

When imposing a movement to the second joint of the leg, the involved CBCO induces a reflex response in the muscle which opposes the direction of the imposed movement (El Manira et al., 1991a): it is a monosynaptic negative feedback termed "resistance reflex" in arthropods that is analogous to the stretch reflex of vertebrates (Clarac et al., 2000). Moreover, besides this simple postural control mechanism involving the CBCO and levator/depressor muscles, the $\mathrm{CBCO}$ is also engaged in interjoint reflex controls during locomotion (El Manira et al., 1991b). More precisely, the CBCO afferents activate motoneurons that command the protractor and remotor muscles controlling the first joint (thoraco-coxal) and responsible for forward and backward movements of the leg.

In the crayfish sensory-motor loops involving the $\mathrm{CBCO}$, several control mechanisms have been described over the past ten years at four levels: (i) the coding properties of the 
sensory neurons may be changed at the source by neurohormonal modulators; (ii) the sensory inflow may be largely reorganized due to the existence of electrical coupling between CBCO afferents; (iii) the synaptic transmission from the $\mathrm{CBCO}$ afferents to the postsynaptic target cells may be controlled by various presynaptic and postsynaptic mechanisms; and finally, (iv) the sensory-motor processing largely depends on polysynaptic pathways, each of the involved interneurons being the target of many control mechanisms.

\section{B - Control of crustacean mechanoreceptors by bioamines and peptides}

The neuromodulation of mechanoreceptor sensitivity by bioamines and peptides has been demonstrated mainly in arthropods. In crustacea, such effects were demonstrated in various mechanoreceptors : the oval organ, a proprioceptor of the gill ventilatory system of crabs; the oval organ is innervated by three afferent neurons with cell bodies located in the thoracic ganglion and these neurons are modulated by octopamine, serotonin and proctolin (Pasztor and Bush, 1987; Pasztor and Bush, 1989); the abdominal muscle receptor organ (MRO) is also modulated by octopamine, serotonin and proctolin (Pasztor and MacMillan, 1990); and the crayfish CBCO is modulated by serotonin (El Manira et al., 1991c; Rossi-Durand, 1993) and proctolin (El Manira et al., 1991c). The addition of serotonin $\left(10^{-6} \mathrm{M}\right.$, Fig. 4) or proctolin $\left(10^{-7} \mathrm{M}\right)$ in the bathing medium surrounding the proprioceptor increases the discharge of the $\mathrm{CBCO}$ sensory neurons in response to a sinusoidal movement imposed to the CBCO strand. Similarly, the rate of the tonic discharge of the neurons coding for position increases in the presence of serotonin $\left(10^{-7} \mathrm{M}\right)$, and some silent ones became tonically active. Interestingly, this excitatory effect on $\mathrm{CBCO}$ sensory neurons by serotonin is changed into an inhibitory effect when the concentration of serotonin is raised to $10^{-4} \mathrm{M}$ 
(Rossi-Durand, 1993). In contrast, proctolin always enhances the sensory discharge of CBCO neurons in a concentration range from $10^{-9}$ to $10^{-4} \mathrm{M}$ (El Manira et al., 1991c).

Then, it appears that the type of effect (excitatory or inhibitory) of some neuromodulators may depend on the neuromodulator concentration. The dual, and even opposite effects produced on a given neuron (e.g., serotonin on the $\mathrm{CBCO}$ in crayfish) may be due to the colocalization of different receptor subtypes on the same neuron. According to the neuromodulator concentration, receptors with distinct affinities will be activated or not: at low concentration, the neuromodulator will preferentially excite high affinity receptors, whereas both high and low affinity receptors will be activated by high concentrations of the neuromodulator. In the same way, the neuromodulator effects can also vary depending on the target mechanoreceptor considered. For example, serotonin and octopamine enhance the sensory responses of the abdominal MRO, but decrease the spiking activity of sensory neurons of the oval organ of lobster (Pasztor and Bush, 1987). Moreover, a neuromodulator may produce opposite effects on the same mechanoreceptor in two different animal species. For example, the effects of octopamine on the activity of the oval organ are excitatory in the Australian crayfish Cherax but inhibitory in the lobster Homarus (Pasztor and MacMillan, 1990). Those differences could be related to other differences in the sensory coding properties observed in the oval organ in different species: whereas in the lobster, the three sensory neurons innervating the oval organ transmit sensory signals both in the form of trains of spikes and membrane potential, in the shore crab, sensory afferent of the oval organ do not elicit spikes and signal only by decremental conduction.

The bioamines octopamine and serotonin and the neuropeptide proctolin are known to be present in the crustacean circulation. However, in some cases neurons containing bioamines are present in the mechanoreceptor itself. For example, serotonin immunohistochemical studies demonstrated the presence of labeled cell bodies in the CBCO 
nerve and the $\mathrm{CBCO}$ elastic strand. In the peripheral part of the $\mathrm{CBCO}$ sensory nerve, serotonin immunoreactivity has been observed in a dense superficial plexus of varicosities and in fine fibers (Fig. 3A). In the CBCO itself (Fig. 3B-D), the serotonin immunoreaction also revealed cell bodies, which size and location in the strand were similar to the sensory neurons (compare with figure 2). These latter data strongly suggest that at least a part of the CBCO sensory neurons colocalize serotonin with acetylcholine. In this proprioceptor, the presence of proctolin immunoreactive structures has not been investigated so far.

To date, we do not know the circumstances that prevail to the liberation of either serotonin or proctolin in the $\mathrm{CBCO}$, and their exact role in motor control remains unknown. Moreover, the presence of serotonin-immunoreactive structures within the $\mathrm{CBCO}$ does not implicate that those structures are responsible for a serotonergic modulation of the $\mathrm{CBCO}$ coding. Furthermore, its opposite dose-dependent effects make the functional role of serotonin even more complicated to assess.

\section{C - Presynaptic inhibition in crustacean proprioceptors}

\section{1) GABAergic control of crustacean proprioceptors}

An efferent control of a crustacean mechanoreceptor was first demonstrated in the abdominal stretch receptor (MRO), the neurons of which offering an exceptional opportunity for intracellular recording (Kuffler and Eyzaguirre, 1955). In brief, in each abdominal segment of lobsters and crayfishes, MRO occur as segmental pairs of modified muscle fibers innervated each by a large sensory neuron. The dendrites of MRO sensory neurons receive synaptic inputs from two inhibitory neurons (Kuffler and Eyzaguirre, 1955), the function of which is to provide feedback inhibition of the receptors during the control of abdominal 
posture (Eckert, 1961). In the crayfish, the effect of GABA on these mechanosensory neurons was demonstrated 40 years ago (Eckert, 1961), and recent immunohistochemical studies coupled to electron microscopy demonstrated that the GABA-immunoreactive varicosities make specialized synaptic contacts with the sensory neurons (Elekes and Florey, 1987a; Elekes and Florey, 1987b). In this case, the GABAergic innervation occurs close to the site where the sensory discharge is elicited, and thereby interferes directly with the coding properties of the mechanosensory neuron. This configuration is thus very similar to the one presented above for the neuromodulation of the sensory neuron activity by bioamines and peptides.

However, GABAergic innervation of the peripheral receptor neurons is not very common in crustacean mechanoreceptors. Except the abdominal stretch receptor, the GABAergic control of crustacean mechanoreceptors was essentially shown in the axonal tree of sensory neurons within the central nervous system. This was first demonstrated in axon terminals of tactile sensory neurons of crayfish telson (Kennedy et al., 1974). The inhibitory interneuron responsible for the production of primary afferent depolarizations (PADs) in those tactile sensory neurons was later intracellularly recorded (Kirk and Wine, 1984; Kirk, 1985), and GABA was proposed as putative neurotransmitter (Kirk and Govind, 1990; Lee and Krasne, 1993). Using electrophysiology and pharmacology, GABA was also demonstrated to mediate PADs in the axonal branches of crayfish CBCO neurons (Cattaert et al., 1992; Cattaert and El Manira, 1999) and hair afferents of the crayfish tailfan (Newland et al., 1996).

In crayfish CBCO neurons, confocal microscopy (Fig. 5) revealed close appositions of GABA-immunoreactive boutons on the sensory terminals within the ganglion (Cattaert and El Manira, 1999). The number of GABA-immunoreactive boutons seems to be very different among the $\mathrm{CBCO}$ sensory axons. Whereas some of them appear to be extensively innervated (Fig. 5B-C), other present very few if any close apposition with GABA-immunoreactive 
boutons. The localization of the GABA central innervation seems to be quite precise within the terminal tree. The arborization of each CBCO sensory terminal is quite simple. It is made of a main axon traveling in the anterior part of the neuropile and giving rise to few small branches. The diameter of the main axon at the first branching point is about 7-10 $\mu \mathrm{m}$ and decreases gradually to $\sim 3 \mu \mathrm{m}$ at a distance of $600 \mu \mathrm{m}$ from the first branching point. GABA-immunoreactive boutons are mainly present at the level of the first branching point of the $\mathrm{CBCO}$ axons in the ganglion (Fig. 5B). This was confirmed by electrophysiological studies (Cattaert and El Manira, 1999). Intracellular recordings from CBCO axons in the region of the first branching point revealed the presence of large PADs occurring in bursts during rhythmic motor activities in the in vitro preparation (Fig. 6).

These PADs are mediated by GABA (Cattaert et al., 1992) via non-A, non-B GABA receptors (El Manira and Clarac, 1991). GABA-mediated PADs are depolarizing because they activate a chloride conductance with an equilibrium potential of $-35 \mathrm{mV}$, the resting potential of CBCO terminals being in the range from -80 to $-70 \mathrm{mV}$ (Cattaert et al., 1992). PADs are blocked by picrotoxin $\left(10^{-4} \mathrm{M}\right)$, a blocker of the chloride channel associated with the GABA-receptor (Fig. 6B). During GABA-mediated PADs, the amplitude of sensory spikes is decreased (Fig. 6A, C), as is the amplitude of the excitatory postsynaptic potential (EPSP) recorded from a motoneuron (Fig. 6C). This decrease in the EPSP amplitude during PADs demonstrates that, although depolarizing, GABA-mediated PADs are inhibitory.

The observation of a relationship between GABAergic PAD discharge and motor activity in the walking network in vitro (Cattaert et al., 1992; El Manira et al., 1991a) suggests that GABAergic innervation of $\mathrm{CBCO}$ axonal branches plays a functional role in movement control. In the absence of rhythmic activity in the central network commanding locomotion, small amplitudes (a few millivolts) GABA-mediated PADs are tonically produced and allow a fine regulation of the gain of the resistance reflex. During rhythmic activity (Fig. 6A), PADs 
occur in large amplitude bursts (20-30 mV) and exert a phasic blockade of the sensory inflow (Cattaert et al., 1992). Such a blockade is useful to prevent a resistance reflex that is not adequate for active movements. Moreover, during active movements, in parallel with the blockade of the monosynaptic resistance reflex, disynaptic pathways are activated that assist the ongoing movement. These assistance reflex pathways involve non-spiking interneurons (Le Ray and Cattaert, 1997).

During bursts of large amplitude PADs, antidromic spikes may be produced in the sensory terminal that are conducted toward the periphery. The role of such antidromic spikes in the control of the sensory coding was demonstrated in the in vitro preparation (Bévengut et al., 1997). When produced with a sufficient frequency, antidromic spikes are able to reduce and even stop the firing of the sensory neuron. Thus, antidromic spikes constitute a mechanism that modulates at the source the activity of the sensory organ. This blocking effect may outlast for few seconds the duration of the antidromic burst. Such a mechanism could represent an economic way of silencing incoming inputs by which the central command escapes from inadequate feedback. However, not all sensory neurons receive PADs, and so antidromic discharge do not occur in every sensory fibers of a given proprioceptor. We may hypothesize that only sensory neurons involved in powerful resistance reflex would be silenced while other unaffected sensory neurons continue to feed the central nervous system with information about joint movement.

\section{2) Histaminergic control of crustacean mechanoreceptors}

Histaminergic neurons were found in the stomatogastric nervous system of the spiny lobster (Claiborne and Selverston, 1984) and in the segmental and stomatogastric nervous system of the crayfish and the lobster (Mulloney and Hall, 1991). Moreover, efferent 
histaminergic presynaptic inhibition of mechanoreceptors was demonstrated in the central axonal tree of CBCO sensory neurons in crayfish (El Manira and Clarac, 1994). Histamine was shown to activate a chloride channel in lobster motoneurons (Hashemzadeh-Gargari and Freschi, 1992) as well as in crayfish CBCO sensory terminals (El Manira and Clarac, 1994).

In the crayfish, the histaminergic innervation of the CBCO terminals was demonstrated using electrophysiological and pharmacological techniques (El Manira and Clarac, 1994). The electrical stimulation of the medial giant fibers (MGF), which trigger the escape response in the crayfish, evokes PADs in intracellularly recorded CBCO terminals (Fig. 7A, B). During this response, the input resistance of the CBCO terminal decreases by $60 \%$ (Fig. 7B2). The combination of cimetidine (an antagonist of histamine) and picrotoxin blocked the MGF-evoked PADs, which therefore, involve two types of receptors (and two neurotransmitters, GABA and histamine) on CBCO sensory terminals.

The direct micro-application of either histamine or GABA close to an intracellularly recorded $\mathrm{CBCO}$ terminal confirms that histamine and GABA involve two different receptor-channels (Fig. 7C-E): picrotoxin but not cimetidine blocks the response to a pulse of GABA (Fig. 7D), whereas cimetidine but not picrotoxin blocks the response to a pulse of histamine (Fig. 7E). The responses to both histamine and GABA are, however, very similar because both neurotransmitters activate a chloride conductance with a reversal potential of $-35 \mathrm{mV}$. The circuitry from MGF to CBCO terminals is likely not monosynaptic and involves parallel pathways activating both GABAergic and histaminergic interneurons.

We may hypothesize that histamine/GABA-mediated presynaptic inhibition would prevent any inappropriate reflex response to occur during the tail-flip. Indeed, during the tail-flip the legs are rapidly extended and moved forward due to the activation of the giant promotor motoneuron. This rapid movement also involves the coxo-basipodite joint, and the $\mathrm{CBCO}$ of each leg is strongly activated. In the absence of a powerful inhibition, the CBCO 
activation would trigger a strong interjoint reflex (El Manira et al., 1991b) inappropriate during this fast movement. The complementary presynaptic inhibitions mediated by both the histaminergic and the GABAergic innervation of the $\mathrm{CBCO}$ sensory terminals prevent this massive sensory feedback from reaching its postsynaptic targets. No immunoreactive labeling of the histaminergic innervation was performed on crayfish $\mathrm{CBCO}$ terminals. Nevertheless, we may assume that histaminergic synapses should be located near the first branching point (similarly to GABA synapses) where large PADs can be produced. We can also suppose that bursts of antidromic spikes should be fired during such histaminergic PADs to silence the $\mathrm{CBCO}$ for a while, allowing the escape reaction to occur without any inappropriate proprioceptive interference.

\section{3) Glutamatergic presynaptic inhibition in CBCO terminals}

Intracellular recordings from $\mathrm{CBCO}$ terminals display two types of depolarizing events: large GABAergic PADs and small slowly developing PADs (sdPADs, Fig. 8A1). Contrary to GABAergic PADs (see paragraph "GABAergic control of crustacean proprioceptors"), sdPADs are not blocked by picrotoxin (Fig. 8A2) and are mediated by glutamate. Direct micro-application (pressure ejection) of glutamate close to a CBCO terminal evokes a small amplitude depolarization and a decrease in the input resistance of the CBCO terminal (Fig. 8B2). These effects persist in the presence of tetrodotoxin $\left(5.10^{-7} \mathrm{M}\right)$ indicating a direct effect of glutamate onto the CBCO terminals (Cattaert and Le Ray, 1998). The glutamate-induced depolarization is not mediated by chloride ions but rather involves a non-specific $\mathrm{Na}^{+} / \mathrm{K}^{+}$channel associated with a kainate-like glutamate receptor (Cattaert and Le Ray, 1998). 
Although no anatomical study has been made on the glutamatergic innervation of CBCO terminals, electrophysiological data indicate that glutamate and GABA innervations are differently distributed within the $\mathrm{CBCO}$ arborization (Fig. 8B). Using a double barrel pressure ejection technique that allows application of either glutamate or GABA at the same site, it was demonstrated that responses to GABA (but not glutamate) are present in the region of the first branching point of the $\mathrm{CBCO}$ terminal (Fig. 8B1; see also paragraph "GABAergic control of crustacean proprioceptors"). In contrast, in the more distal parts of the CBCO arborization, both GABA and glutamate evoke PADs and sdPADs, respectively (Fig. 7B2).

The fact that glutamatergic and GABAergic inhibitions are differently located within the terminal arborization suggests that those inhibitory mechanisms do not play the same functional role. The functional role of glutamate-evoked sdPADs is directly linked to the motoneuronal activity (Cattaert and Le Ray, 1998), whereas the GABAergic inhibition is rather linked to the activity of the central pattern generator (Cattaert et al., 1992; El Manira et al., 1991a). Based on several electrophysiological evidences, we assume that sdPADs are due to a motoneuronal glutamatergic feedback onto $\mathrm{CBCO}$ terminals: (i) motoneurons are glutamatergic; (ii) the electrical stimulation of the motor nerves evokes DNQX (a non-NMDA antagonist of glutamate receptors)-sensitive sdPADs in CBCO terminals, which (iii) persist in the presence of a high divalent cation solution that suppresses polysynaptic pathways. Therefore, glutamatergic sdPADs are likely involved in an automatic gain control of the monosynaptic resistance reflex (Cattaert and Le Ray, 1998). The more active the motoneuron, the more it inhibits its sensory afferent signals (Clarac et al., 2000).

4) Presynaptic inhibition in which the involved neurotransmitter remains unknown 
In addition to the preceding examples, presynaptic inhibition of primary afferents was demonstrated using an electrophysiological approach in several other crustacean sensory neurons. However, in many cases, presynaptic inhibition was studied as a functional mechanism but the nature of the neurotransmitter involved was not investigated. This was the case in crayfish leg for the thoraco-coxal muscle receptor organ (TCMRO) (Sillar and Skorupski, 1986), and the contact-sensitive mechanoreceptive afferents from the dactyl (DSA) (Marchand et al., 1997). In the TCMRO, a muscle receptor organ of the first joint of the leg, the two non-spiking sensory neurons ( $\mathrm{S}$ and $\mathrm{T}$ fibers) that innervate this proprioceptor display pronounced modulations of their membrane potential in phase with the locomotor rhythm in vitro (Sillar and Skorupski, 1986). A very similar observation was made in intracellular recordings from the non-spiking afferent neurons of the oval organ in the shore crab Carcinus maenas. During the expression of the forward ventilation the membrane potential of the sensory neuron was rhythmically hyperpolarized in phase with the ventilatory rhythm (DiCaprio, 1999). These oscillations are produced by inhibitory synapses, are accompanied by a decrease in input resistance, and involve ions with an equilibrium potential of approximately $-78 \mathrm{mV}$ (DiCaprio, 1999). In these two examples of non-spiking sensory neurons the neurotransmitter involved in efferent control was not identified. This is also the case of some spiking mechanosensory neurons. For example, intracellular recordings performed from axon terminals of dactyl sensory afferents (DSA) in the crayfish demonstrated the existence of inhibitory PADs of sensory origin (Marchand et al., 1997). These PADs were observed both in hair and force-sensitive afferents and were produced in response to mechanical stimulation of other hairs on the same dactyl (Marchand et al., 1997). Contrary to TCMRO, oval organ and CBCO afferents, the PADs observed in DSA afferents were exclusively of sensory origin. 


\section{D - Glutamatergic long-term potentiation in CBCO terminals}

Surprisingly, glutamate is not involved only in an inhibitory mechanism, but is also responsible for a long-term potentiation (LTP) of the CBCO-motoneuron synapse (Le Ray and Cattaert, 1999). After long periods (several hours) of complete motoneuronal inactivity, the efficacy of the CBCO-motoneuron synapse is considerably decreased. Using paired intracellular recordings from a presynaptic CBCO terminal and a postsynaptic depressor motoneuron (Fig. 9A), it was shown that the occurrence of spiking activity in the motoneuron triggers a LTP of the CBCO-motoneuron synapse to develop (Fig. 9A2-4; Le Ray and Cattaert, 1999). After this postsynaptic induction, the mean amplitude of the unitary EPSPs evoked by $\mathrm{CBCO}$ spikes was increased by up to $300 \%$. This potentiation persisted for up to five hours after the induction without any further postsynaptic activation.

This sensory-motor LTP still occurs in the presence of a high divalent cation solution but is prevented when the MN activation is performed in the presence of GPT (glutamate pyruvate transaminase, an enzyme that rapidly degrades glutamate) in the synaptic cleft. Moreover, activating one motoneuron does not trigger the potentiation of the $\mathrm{CBCO}$ synapses onto other, still inactive motoneurons. Therefore, this LTP is produced by a direct release of glutamate from the postsynaptic motoneuron onto its own sensory afferents (retrograde system of glutamate transmission from the postsynaptic motoneuron; Le Ray and Cattaert, 1999).

Direct micro-application of glutamate in the region of the CBCO terminals is sufficient to induce LTP of the CBCO-motoneuron synapse (Fig. 9B). After such a local glutamate ejection, the compound EPSP evoked by the electrical stimulation of the CBCO sensory nerve is increased (up to 200\%; Fig. 9B2-3). However, in the presence of the glutamate metabotropic receptor antagonist 4C3 HPG, the same local ejection of glutamate does not elicit any potentiation of the sensory-motor synapse (Fig. 9B3; Le Ray and Cattaert, 1999). 
These results indicate that the sensory-motor LTP in crayfish involves the activation of a metabotropic glutamate receptor located presynaptically on the CBCO terminal and suggest that the expression site of LTP is presynaptic. This has been confirmed by quantal analyses on unitary sensory-motor EPSPs (Le Ray and Cattaert, 1999).

Interestingly, the glutamatergic feedback originating from motoneurons thus exerts dual antagonistic effects onto $\mathrm{CBCO}$ sensory terminals. However, both efferent controls do not occur under the same conditions. The fast inhibitory effect is observed during high motoneuronal activity, and would prevent the motoneuron from being over-activated (see above). In contrast, the slower long-term enhancement occurs after long periods of motor silence and would instead restore a functional sensory-motor synapse.

\section{E - Functional considerations}

We have presented several examples of efferent control of mechanosensory neurons in crustacea, mainly based upon electrophysiological and pharmacological evidences. Indeed, most of the crustacean mechanosensory neurons studied so far seem to be the target of such controls, but the involved mechanisms have not been analyzed in detail and were therefore not mentioned in this review. For example, PADs have been also recorded from terminals of sensory neurons innervating the cuticular stress detectors (Marchand and Leibrock, 1994).

As stated in the introduction, proprioceptive inputs may adapt the output motor command and, in turn proprioceptive inputs may be reshaped by the central neural network. Indeed, sensory information feeds the central neural network at different levels (motoneurons and interneurons) and the interactions may be very complex (Cattaert and Le Ray, 2001; Clarac et al., 2000). Sensory-motor loops are key elements of the organization and control of 
actual movements. On the other hand, sensory-motor loops must be modulated in order to adapt to the ongoing movement strategy. For example, during locomotion the stance phase is mainly involved in postural control and is based on negative feedback reflexes. In contrast, during the initiation of the swing phase negative feedback reflexes are often replaced by positive feedback reflexes. Reflex reversal was observed in crustacean walking legs (DiCaprio and Clarac, 1981; El Manira et al., 1990; Le Ray and Cattaert, 1997; Skorupski and Sillar, 1986; Skorupski, 1996), crustacean antennae (Vedel, 1982), in insect walking legs (Bässler, 1986), and during locomotion in the cat (Forssberg et al., 1975) and in human (Duysens et al., 1990). However, reflex reversal is one extreme case in which the sign of a reflex is reversed. Indeed, the strength of reflexes may be modulated continuously during limb movements due to presynaptic inhibition of primary afferents, as was shown in crustacea (Sillar and Skorupski, 1986) and mammals (Dubuc et al., 1985; Dubuc et al., 1988; Gossard, 1996). It is therefore not surprising that presynaptic inhibitory mechanisms are so widely present in the different sensory-motor systems controlling movements in invertebrates and vertebrates. However, the superposition of so many different presynaptic control mechanisms is unexpected. As reviewed above, on the same sensory neuron and at the same location, GABAergic, glutamatergic and histaminergic synapses can coexist. A very similar situation was observed in the slit organ of spiders (Fabian-Fine et al., 2000) where GABAergic, glutamatergic and other unidentified synapses are present on the same sensory neuron cell body. In the locust too, GABAergic and non-GABAergic synapses are colocalized on terminals of campaniform sensilla on the trochanter (Watson and England, 1991).

In $\mathrm{CBCO}$ terminals, the results reported in this review suggest that GABA, histamine and glutamate synapses are involved in distinct inhibitory mechanisms (switch between resistance and assistance reflex modes for GABA, escape reaction for histamine, and local automatic gain control for glutamate). However, such a clear assignation for the different 
inhibitory neurotransmitters cannot be generalized. For example, in insects the automatic gain control in sensory afferents is mediated by GABA through a disynaptic pathway (Burrows and Laurent, 1993) whereas in the crayfish it is monosynaptic and mediated by glutamate (Cattaert and Le Ray, 1998). Nevertheless, both automatic gain control systems share a common feature: both are unable to elicit antidromic spikes, which would be inappropriate in such a fine adjustment of the sensory-motor gain (see above). In the case of the locust, the chloride conductance involved in the GABAergic control has a reversal potential close to the resting potential of the sensory neuron. Similarly, in the crayfish the glutamatergic inhibition involves a mixed $\mathrm{Na}^{+} / \mathrm{K}^{+}$conductance, the reversal potential of which is also very close to the resting potential of the $\mathrm{CBCO}$ sensory neuron. If, in contrast, this glutamatergic inhibitory control had involved a chloride conductance, antidromic spikes could have been produced (because of the depolarized reversal potential of chloride ions in crayfish sensory neurons) and caused an all or none effect incompatible with a fine adjustment of the gain.

Another difference between the automatic gain controls in the insect and the crayfish lies in the origin of the gain control mechanism. Whereas it originates from sensory activity (input) in the locust (Burrows and Laurent, 1993; Burrows and Matheson, 1994), the local gain control in crayfish $\mathrm{CBCO}$ is exclusively based on the activity of the postsynaptic motoneuron (output). Nevertheless, such a clear-cut distinction that is globally true does not hold in some particular cases: in the crayfish, we found $<5 \%$ sensory CBCO terminals that received PADs triggered by other $\mathrm{CBCO}$ afferents (unpublished observation). Therefore, such CBCO-triggered PADs may participate in a gain control mechanism very similar to the one described in the locust. It is interesting to note that, in this case again, the CBCO-triggered PADs have a reversal potential close to the resting potential of the sensory neuron and are therefore not carried by chloride ions. In contrast, in the dactyl sensory afferent of the crayfish, PADs of sensory origin also exist (Marchand et al., 1997). Interestingly, those PADs are 
GABAergic with a chloride reversal potential around $-35 \mathrm{mV}$, and antidromic spikes can be evoked. In this case, PADs do not seem to be involved in a fine and continuous gain control mechanism but in a lateral inhibition principle (contrast enhancer) where the most activated sensory neuron will totally inhibit the neighboring sensory afferents.

From a functional point of view, the effect of an inhibitory synapse largely depends on its location on the terminal arborization and the distribution of $\mathrm{Na}^{+}$channels at that site (Cattaert et al., 2001). Indeed, it seems that, at least in the crayfish CBCO, the localization of inhibitory synapses obeys strict rules. From electrophysiological data, we have shown that in the distal branches only passive conduction occurs (Cattaert et al., 1992), and the transition from active to passive conduction seems to occur in the vicinity of the first branching point where GABAergic synapses are concentrated (Cattaert and El Manira, 1999; Fig. 5). Simulations have shown that this location confers to the GABA synapses their optimal efficacy (Cattaert et al., 2001): (i) the incoming sensory spike that is shunted by chloride channels activated by GABA, is not restored in more distal regions, and the resulting EPSP in the postsynaptic neuron is reduced accordingly; (ii) antidromic spikes triggered by large PADs can only be conveyed toward the periphery (the CBCO) because the $\mathrm{Na}^{+}$channel concentration is only sufficient proximally from the GABA sites. By contrast, glutamate sdPADs are always of small amplitude (see above) but produce a powerful shunting of the incoming sensory message without evoking any antidromic spikes (Cattaert and Le Ray, 1998). Although this could be achieved anywhere in the passive part of the sensory terminal, electrophysiological data indicate that glutamate synapses are located close to the endings suggesting the existence of a sensory-motor synapse complex, in which the motoneuronal control synapse is closely related to the output sensory synapse. Further studies using electron microscopy are required to establish this hypothesis. In other species, the precise distribution of efferent control synapse locations does not seem to prevail. Indeed, in insects (Watson and 
England, 1991) and spiders (Fabian-Fine et al., 2000), different efferent control synapses are colocalized at the same site on the sensory neurons. In the locust, it was proposed that competition could occur between the various control mechanisms, which may interact through presynaptic inhibition (Watson, 1992).

The data reviewed here clearly demonstrate that mechanosensory afferents are the site of various modulatory mechanisms. Although some data indicate that such mechanisms operate also in other animal species, more studies are required before generalizing the findings obtained in crustacea. In addition, sensory afferents represent only input elements of neural network involved in motor control. The function and the modulation of sensory-motor connections needs to be analyzed in this wider context. Not only sensory neurons undergo modulatory controls, but motoneurons and interneurons are also modulated, allowing central pattern generator to be remodeled (Katz, 1998; Nusbaum et al., 2001). All these changes allow the nervous system to adapt to the constraints and the animal to survive in a changing milieu. Indeed modulatory mechanisms are not only responsible for changes in individual behavior but are also involved in the control of social interactions (Yeh et al., 1996; Yeh et al., 1997). Therefore, there is a urgent need for neuroscientists to keep in mind a physiological approach, and replace their findings in this more general perspective.

\section{G - Acknowledgments}

This work was supported by the Centre National de la Recherche Scientifique (CNRS). Morgane Le Bon is a fellow of the Ministère de la Recherche (France). 


\section{H - References}

Bässler, U. (1986) Afferent control of walking in the stick insect Cuniculina impigra. II. Reflex reversal and the release of the swing phase in the restrained foreleg. J.Comp.Physiol.[A], 158:351-361.

Bévengut, M., Clarac, F., and Cattaert, D. (1997) Antidromic modulation of a proprioceptor sensory discharge in crayfish. J.Neurophysiol., 78:1180-1183.

Brown, T.G. (1911) The intrinsic factors in the act of progression in the mammal. Proc.R.Soc.Lond.B.Biol.Sci., 84:308-319.

Burrows, M. and Laurent, G. (1993) Synaptic potentials in the central terminals of locust proprioceptive afferents generated by other afferents from the same sense organ. J.Neurosci., 13:808-819.

Burrows, M. and Matheson, T. (1994) A presynaptic gain control mechanism among sensory neurons of a locust leg proprioceptor. J.Neurosci., 14:272-282.

Cattaert, D. and El Manira, A. (1999) Shunting versus inactivation: analysis of presynaptic inhibitory mechanisms in primary afferents of the crayfish. J.Neurosci., 19:6079-6089.

Cattaert, D., El Manira, A., and Bevengut, M. (1999) Presynaptic inhibition and antidromic discharges in crayfish primary afferents. J.Physiol.Paris, 93:349-358.

Cattaert, D., El Manira, A., and Clarac, F. (1992) Direct evidence for presynaptic inhibitory mechanisms in crayfish sensory afferents. J.Neurophysiol., 67:610-624.

Cattaert, D. and Le Ray, D. (1998) Direct glutamate-mediated presynaptic inhibition of sensory afferents by the postsynaptic motor neurons. Eur.J.Neurosci., 10:3737-3746. 
Cattaert, D. and Le Ray, D. (2001a) Adaptive motor control in crayfish. Prog.Neurobiol.2001.Feb.;63.(2.):199.-240., 63:199-240.

Cattaert, D., Libersat, F., and El Manira, A. (2001) Presynaptic inhibition and antidromic spikes in primary afferents of the crayfish: a computational and experimental analysis. J.Neurosci.2001.Feb.1.;21.(3.):1007.-21., 21:1007-1021.

Claiborne, B.J. and Selverston, A.I. (1984) Histamine as a neurotransmitter in the stomatogastric nervous system of the spiny lobster. J.Neurosci., 4(3):708-721.

Clarac, F., Cattaert, D., and Le Ray, D. (2000) Central control components of a 'simple' stretch reflex. Trends Neurosci.2000.May.;23.(5.):199.-208., 23:199-208.

DiCaprio, R.A. (1999) Gating of afferent input by a central pattern generator. J.Neurophysiol., 81:950-953.

DiCaprio, R.A. and Clarac, F. (1981) Reversal of a walking leg reflex elicited by a muscle receptor. J.Exp.Biol., 90:197-203.

Dubuc, R., Cabelguen, J.-M., and Rossignol, S. (1985) Rhythmic antidromic discharges of single primary afferents recorded in cut dorsal root filaments during locomotion in the cat. Brain Res., 359:375-378.

Dubuc, R., Cabelguen, J.-M., and Rossignol, S. (1988) Rhythmic fluctuations of dorsal root potentials and antidromic discharges of primary afferents during fictive locomotion in the cat. J.Neurophysiol., 60:2014-2036.

Duysens, J., Trippel, M., Horstmann, G.A., and Dietz, V. (1990) Gating and reversal of reflexes in ankle muscles during human walking. Exp.Brain Res., 82:351-358. 
Eckert, R.O. (1961) Reflex relationships of the abdominal stretch receptors of the crayfish. I. Feedback inhibition of the receptors. J.Cell.and Comp.Physiol., 57:149-162.

El Manira, A., Cattaert, D., and Clarac, F. (1990) Reflex reversal and presynaptic control of sensory afferents in crustacea. Eur.J.Neurosci., S3:183-183.

El Manira, A., Cattaert, D., and Clarac, F. (1991a) Monosynaptic connections mediate resistance reflex in crayfish (Procambarus clarkii) walking legs. J.Comp.Physiol.[A], $168: 337-349$.

El Manira, A. and Clarac, F. (1991) GABA-mediated presynaptic inhibition in crayfish primary afferents by non-A, non-B GABA receptors. Eur.J.Neurosci., 3:1208-1218.

El Manira, A. and Clarac, F. (1994) Presynaptic inhibition is mediated by histamine and GABA in the crustacean escape reaction. J.Neurophysiol., 71:1088-1095.

El Manira, A., DiCaprio, R.A., Cattaert, D., and Clarac, F. (1991b) Monosynaptic interjoint reflexes and their central modulation during fictive locomotion in crayfish. Eur.J.Neurosci., 3:1219-1231.

El Manira, A., Rossi-Durand, C., and Clarac, F. (1991c) Serotonin and proctolin modulate the response of a stretch receptor in crayfish. Brain Res., 541:157-162.

Elekes, K. and Florey, E. (1987a) Immunocytochemical evidence for the GABAergic innervation of the stretch receptor neurons in crayfish. Neuroscience, 22:1111-1122.

Elekes, K. and Florey, E. (1987b) New types of synaptic connections in crayfish stretch receptor organs: an electron microscopic study. J.Neurocytol., 16:613-626. 
Fabian-Fine, R., Meinertzhagen, I.A., and Seyfarth, E.A. (2000) Organization of efferent peripheral synapses at mechanosensory neurons in spiders. J.Comp.Neurol.2000.May.1.;420.(2.):195.-210., 420:195-210.

Forssberg, H., Grillner, S., and Rossignol, S. (1975) Phase dependent reflex reversal during walking in chronic spinal cats. Brain Res., 85:103-107.

Frank, K. and Fuortes, M.G.F. (1957) Presynaptic and postsynaptic inhibition of monosynaptic reflexes. Fed.Proc.Fed.Am.Soc.Exp.Biol., 16:39-40.

Gossard, J.-P. (1996) Control of transmission in muscle group IA afferents during fictive locomotion in the cat. J.Neurophysiol., 76:4104-4112.

Gossard, J.-P., Cabelguen, J.-M., and Rossignol, S. (1989) Intra-axonal recordings of cutaneous primary afferents during fictive locomotion in the cat. J.Neurophysiol., 62:1177-1188.

Hashemzadeh-Gargari, H. and Freschi, J.E. (1992) Histamine activates chloride conductance in motor neurons of the lobster cardiac ganglion. J.Neurophysiol., 68:9-15.

Katz, P.S. (1998) Neuromodulation intrinsic to the central pattern generator for escape swimming in Tritonia. Ann.N.Y.Acad.Sci., 860:181-188.

Kennedy, D., Calabrese, R.L., and Wine, J.J. (1974) Presynaptic inhibition: primary afferent depolarization in crayfish neurons. Science, 186:451-454.

Kiehn, O. and Kjaerulff, O. (1998) Distribution of central pattern generators for rhythmic motor outputs in the spinal cord of limbed vertebrates. Ann.N.Y.Acad.Sci., 860:110-129. 
Kirk, M.D. (1985) Presynaptic inhibition in the crayfish CNS: pathways and synaptic mechanisms. J.Neurophysiol., 54:1305-1325.

Kirk, M.D. and Govind, C.K. (1990) Presynaptic inhibition of primary afferent synapses in the crayfish. In: Frontiers in Crustacean Neurobiology. K. Wiese, W.-D. Krenz, J. Tautz, H. Reichert, and B. Mulloney, eds. Birkha|ser Verlag. Basel, pp. 140-149.

Kirk, M.D. and Wine, J.J. (1984) Identified interneurons produce both primary afferent depolarization and presynaptic inhibition. Science, 225:854-856.

Kuffler, S.W. and Eyzaguirre, C. (1955) Synaptic inhibition in an isolated nerve cell. J.Gen.Physiol., 39:155-184.

Le Ray, D. and Cattaert, D. (1997) Neural mechanisms of reflex reversal in coxo-basipodite depressor motor neurons of the crayfish. J.Neurophysiol., 77(4):1963-1978.

Le Ray, D. and Cattaert, D. (1999) Active motor neurons potentiate their own sensory inputs via glutamate- induced long-term potentiation. J.Neurosci., 19:1473-1483.

Lee, S.C. and Krasne, F.B. (1993) Ultrastructure of the circuit providing input to the crayfish lateral giant neurons. J.Comp.Neurol., 327:271-288.

Marchand, A.R., Barnes, W.J.P., and Cattaert, D. (1997) Primary afferent depolarizations of sensory origin within contact- sensitive mechanoreceptive afferents of a crayfish leg. J.Neurophysiol., 77(6):3340-3354.

Marchand, A.R. and Leibrock, C.S. (1994) Functional aspects of central electrical coupling in mechanoreceptor afferents of crayfish. Brain Res., 667:98-106. 
Mulloney, B. and Hall, W.M. (1991) Neurons with histaminelike immunoreactivity in the segmental and stomatogastric nervous systems of the crayfish Pacifastacus leniusculus and the lobster Homarus americanus. Cell Tissue Res., 266:197-207.

Newland, P.L., Aonuma, H., Sato, M., and Nagayama, T. (1996) Presynaptic inhibition of exteroceptive afferents by proprioceptive afferents in the terminal abdominal ganglion of the crayfish. J.Neurophysiol., 76:1047-1058.

Nusbaum, M.P., Blitz, D.M., Swensen, A.M., Wood, D., and Marder, E. (2001) The roles of co-transmission in neural network modulation. Trends Neurosci., 24:146-154.

Pasztor, V.M. and Bush, B.M.H. (1987) Peripheral modulation of mechanosensitivity in primary afferent neurons. Nature, 326:793-795.

Pasztor, V.M. and Bush, B.M.H. (1989) Primary afferent responses of a crustacean mechanoreceptor are modulated by proctolin, octopanine, and serotonin. J.Neurobiol., $20: 234-254$

Pasztor, V.M. and MacMillan, D.L. (1990) The actions of proctolin, octopamine and serotonin on crustacean proprioreptors show species and neurone specificity. J.Exp.Biol., $152: 485-504$

Rossi-Durand, C. (1993) Peripheral proprioceptive modulation in crayfish walking leg by serotonin. Brain Res., 632:1-15.

Selverston, A.I. (1985) Model neural networks and behavior, Plenum Press, New-York and London, pp. 1-548, 
Sherrington, C.S. (1910) Flexion-reflex of the limb, crossed extension reflex stepping and standing. J.Physiol.(Lond), 40:28-121.

Sillar, K.T. and Skorupski, P. (1986) Central input to primary afferent neurons in crayfish, Pacifastacus leniusculus, is correlated with rhythmic motor output of thoracic ganglia. J.Neurophysiol., 55:678-688.

Skorupski, P. (1996) Octopamine induces steady-state reflex reversal in crayfish thoracic ganglia. J.Neurophysiol., 76:93-108.

Skorupski, P. and Sillar, K.T. (1986) Phase-dependent reversal of reflexes mediated by the thoracocoxal muscle receptor organ in the crayfish, Pacifastacus leniusculus. J.Neurophysiol., 55:689-695.

Vedel, J.P. (1982) Reflex reversal resulting from active movements in the antenna of the rock lobster. J.Exp.Biol., 101:121-133.

Watson, A.H.D. (1992) Presynaptic modulation of sensory afferent in the invertebrate and vertebrate nervous system. Comp.Biochem.Physiol., 103 (2):227-239.

Watson, A.H.D. and England, R.C.D. (1991) The distribution and interactions between GABA-immunoreactive and non-immunoreactive processes presynaptic to afferents from Campaniform Sensilla on the trochantes of the locust leg. Cell Tissue Res., 266:331-341.

Wilson, D.M. (1961) The central nervous control of flight in locust. J.Exp.Biol., 38:471-490.

Wolf, H. and Burrows, M. (1995) Proprioceptive sensory neurons of a locust leg receive rhythmic presynaptic inhibition during walking. J.Neurosci., 15:5623-5636. 
Yeh, S.R., Fricke, R.A., and Edwards, D.H. (1996) The effect of social experience on serotonergic modulation of the escape circuit of crayfish [see comments]. Science, 271:366-369.

Yeh, S.R., Musolf, B.E., and Edwards, D.H. (1997) Neuronal adaptations to changes in the social dominance status of crayfish. J.Neurosci., 17:697-708. 


\section{Figure legends}

Figure 1: The crayfish locomotor nervous system. A: Located at the base of each leg, the coxo-basipodite chordotonal organ $(\mathrm{CBCO})$ monitors the vertical movements of the leg. Upward movements are commanded by the couple of anterior and posterior levator muscles (LEV) and downward movements are commanded by the depressor muscle (DEP). B: The in vitro preparation of the locomotor nervous system consists of the last three thoracic ganglia (Th 3-5) dissected out along with the innervation of one of the legs (here the left fifth leg). All the proximal nerves are dissected out and comprise the motor nerves innervating the levator and depressor muscles and the sensory nerve connected to the CBCO strand.

Figure 2: The coxo-basipodite chordotonal organ of the crayfish. A: The $\mathrm{CBCO}$ is composed of an elastic strand in which 40 sensory cell bodies are embedded. A1, schematic drawing of the $\mathrm{CBCO}$ in which the length of the strand has been shortened, A2-3, photomicrograph and interpretation drawing of the proximal part of the $\mathrm{CBCO}$ showing the sensory cell bodies and the insertion of the sensory nerve. The axons of the sensory cells form the sensory nerve that projects to the ipsilateral hemiganglion. B: Tridimensional reconstruction of a $\mathrm{CBCO}$ sensory terminal. The inset shows its arrangement within the neuropile of the fifth left hemiganglion (Th 5).

Figure 3: Serotonergic modulation of the $\mathrm{CBCO}$ coding properties. A: Control response of a stretch (downward movement)-sensitive CBCO sensory neuron recorded from the terminal. B: Same response during the exposure of the $\mathrm{CBCO}$ strand to $10^{-6} \mathrm{M}$ serotonin. Adapted from Rossi-Durand, 1993. 
Figure 4: Serotonin immunoreactivity in the CBCO. A: Immuno-staining of serotonin fine fibers and varicosities within the peripheral sensory nerve. B: Immuno-labeling of serotonergic cell bodies within the CBCO strand. C: Detail from B. D: Schematic drawing of the organization of the serotonergic neurons within the $\mathrm{CBCO}$ strand (compare with the location of the sensory neurons in Fig. 2). Adapted from Rossi-Durand, 1993.

Figure 5: Localization of the GABAergic synapses on CBCO sensory terminals. A: Confocal microscopy analysis showing the general arrangement of the $\mathrm{CBCO}$ sensory terminals within the fifth left hemiganglion (Th 5). All of the sensory terminals were stained by an anterograde migration of Neurobiotin from the cut sensory nerve. B: Detail of a part of a CBCO terminal (first branching point) showing the location of GABAergic close apposition sites (open circles). C: Photomicrograph of the same region displaying a sensory terminal (star) surrounded by GABAergic boutons (clear spots).

Figure 6: GABAergic PADs recorded intracellularly from CBCO sensory terminals. A: During rhythmic motor activity (see rhythmic bursts on the depressor neurogram), bursts of large primary afferent depolarizations (PADs) occur in relation with the ongoing rhythm.

During such PADs, the orthodromic sensory spikes are shunted. B: During large PAD bursts, antidromic spikes can be produced. After 10 minutes of picrotoxin (PTX) perfusion, the amplitude of PADs is reduced and antidromic spikes are no longer triggered. After 15 minutes of picrotoxin perfusion, PADs are completely prevented. C: PADs are inhibitory. Compared to a sensory spike occurring in the absence of PAD (1), when superimposed on a PAD (2) the amplitude of the orthodromic CBCO sensory spike is shunted, and the EPSP it triggers in a postsynaptic motoneuron (here, a levator motoneuron, $\mathrm{MN}$ ) is reduced in amplitude. 
Figure 7: Histaminergic presynaptic inhibition in CBCO terminals. A: Intracellular recording was performed in a $\mathrm{CBCO}$ sensory terminal (CBT) while the medial giant fibers (MGF) were electrically stimulated. B: The MGF stimulation evoked a large histaminergic depolarization in the sensory terminal (1) that was accompanied by a large decrease in input resistance monitored by intracellular injection of squares of hyperpolarizing current (2). C-E: The local pressure application of either GABA or histamine onto a CBCO terminal evokes PADs that are blocked by picrotoxin (PTX) and cimetidine, respectively, indicating that two distinct receptor channels are involved.

Figure 8: Distinction between GABAergic and glutamatergic PADs. A1: Various depolarizing events can be recorded from a $\mathrm{CBCO}$ sensory terminal (CBT). Beside the large GABAergic PADs, small slowly-developing PADs (sdPADs) can occur in rhythmic preparations. A2: Those sdPADs resist to the perfusion of picrotoxin indicating that they are not mediated by the same chloride current as the large GABAergic PADs. B: GABAergic PADs are recorded from a large part of the CBCO terminal (1 and 2), whereas glutamatergic sdPADs are restricted to the finest ending parts of the sensory terminal (2). Both produce a large decrease in the input resistance (monitored by intracellular injection of square pulses of hyperpolarizing current) of the sensory neuron but only GABA evokes a large depolarization.

Figure 9: Glutamatergic long term potentiation of the sensory-motor synapse. A1: Paired intracellular recordings were performed from a $\mathrm{CBCO}$ sensory terminal (CBT) and a postsynaptic motoneuron (MN). A2: After a long period of motoneuronal silence, the amplitude of the sensory-evoked EPSP is rather small. Top traces: overdraw of ten unitary EPSPs recorded from the Dep MN; middle trace : average of 50 unitary EPSPs recorded from the Dep MN; bottom trace: average of 50 presynaptic spikes recorded from the CBT. 
A3-4: Following the activation of the postsynaptic motoneuron alone (3), the amplitude of the sensory-evoked EPSP dramatically increased in a quantal manner (4). B1: Intracellular recording was performed from a motoneuron and the CBCO sensory nerve was electrically stimulated (threshold intensity, CB St) before and after the local pressure application of glutamate onto the $\mathrm{CBCO}$ terminals. A2: After glutamate ejection, the amplitude of the sensory-evoked EPSP largely increased. A3: This increase (square) was prevented by the bath perfusion of the glutamatergic metabotropic receptor antagonist 4C3 HPG (circles). 
A

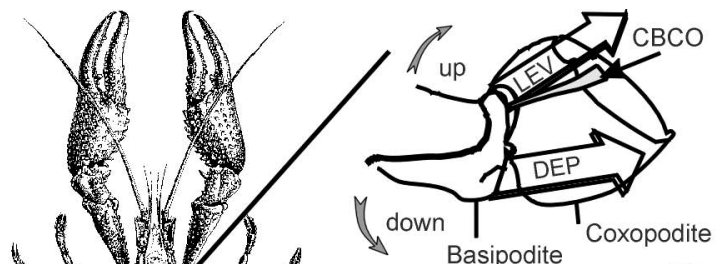

B
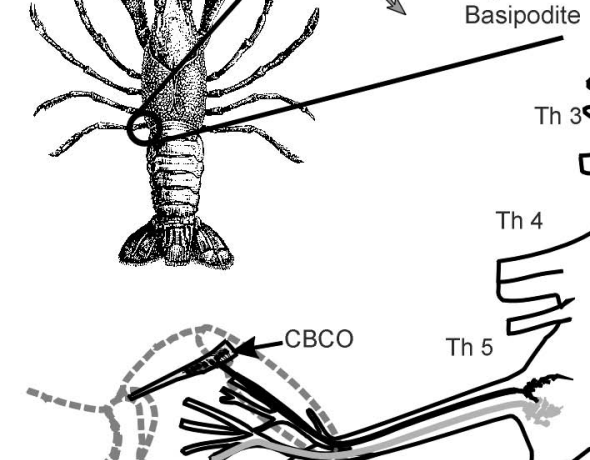

$\leftrightarrow$ \&EP

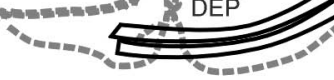

Th 5

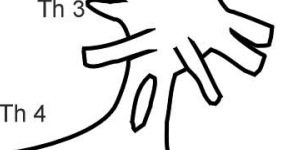

Th
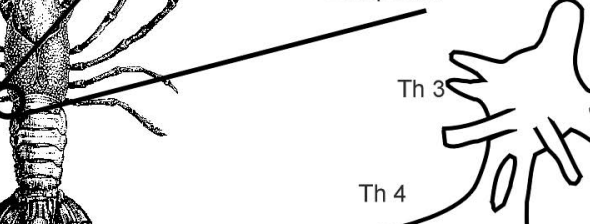

$2 \%, 8$, 


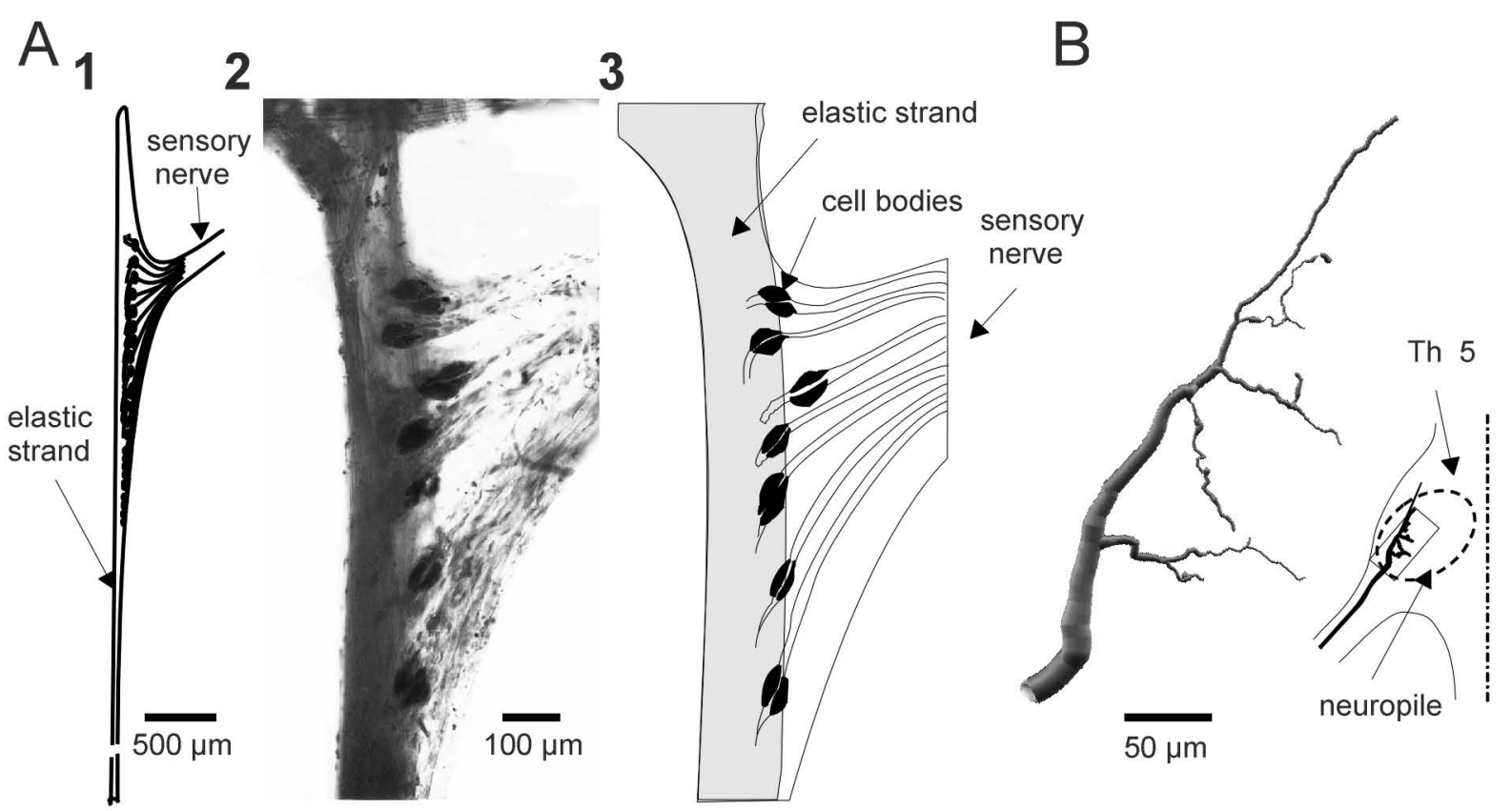


A Control

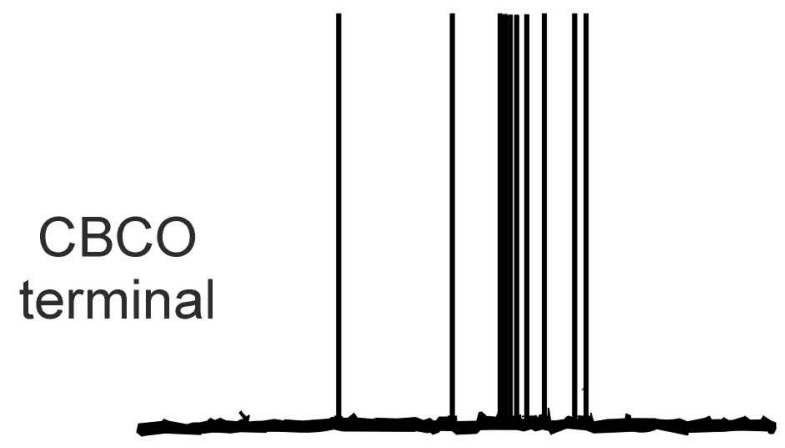

B Serotonin $10^{-6} \mathrm{M}$
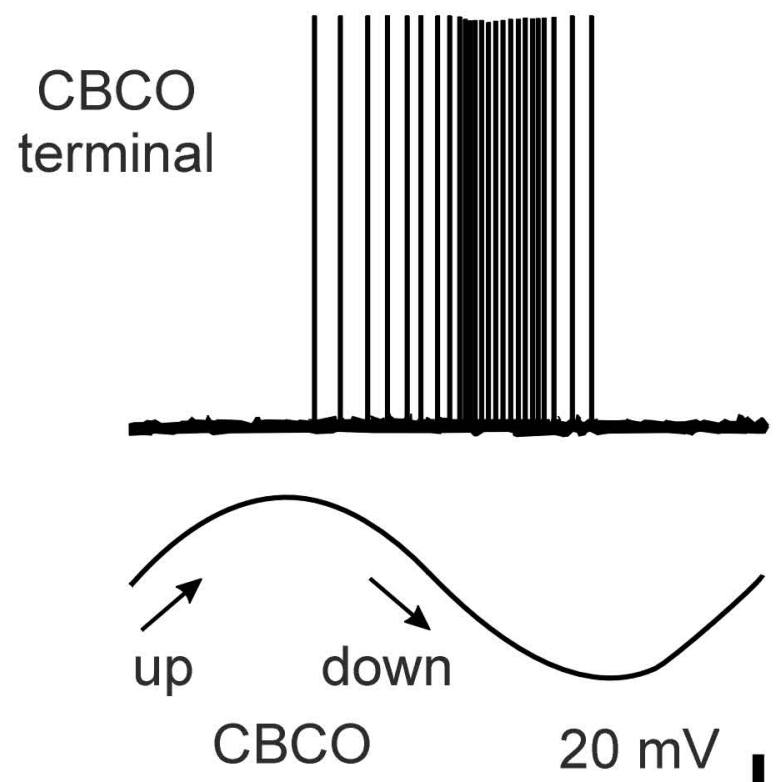

Movement $2 \mathrm{~s}$ 
A

B

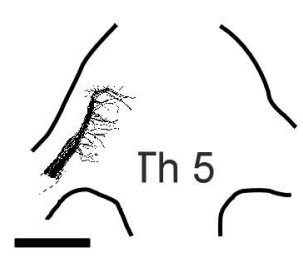

$500 \mu \mathrm{m}$
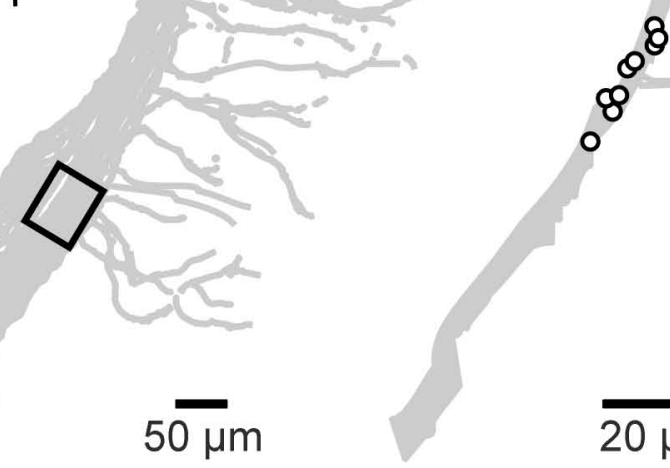

$20 \mu \mathrm{m}$

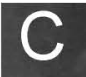


Depressor nerve

\section{$\mathrm{CBCO}$}

terminal

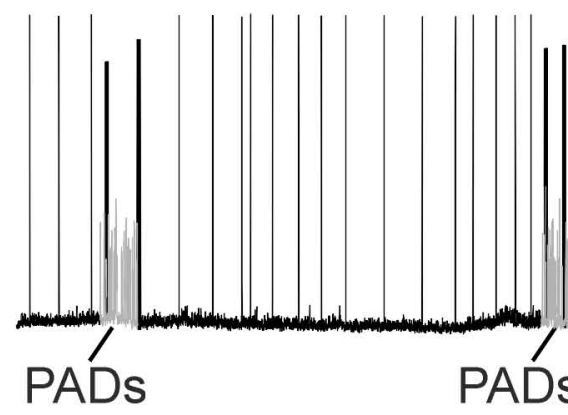

B

Control PTX $10^{-4} \mathrm{M}$ PTX $10^{-4} \mathrm{M}$ 10 min

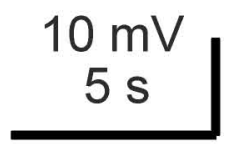

15 min

\section{$\mathrm{CBCO}$} terminal 
A

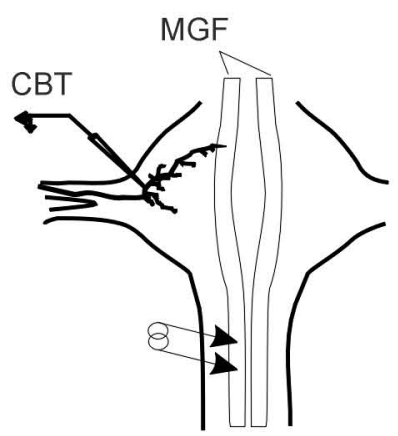

C

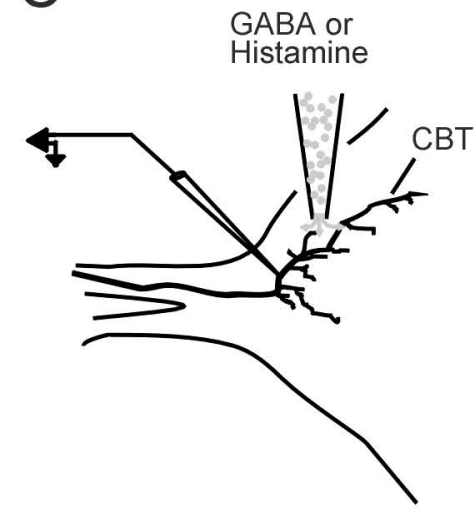

B

1

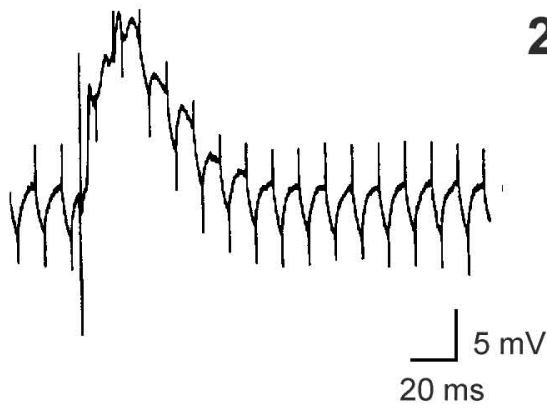

2

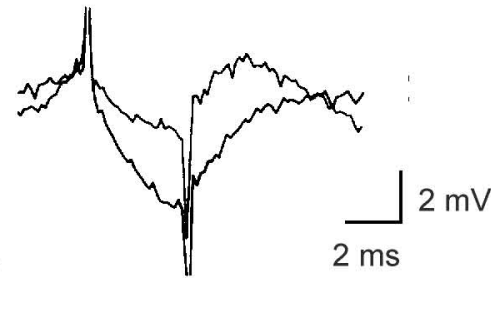

D

CBT
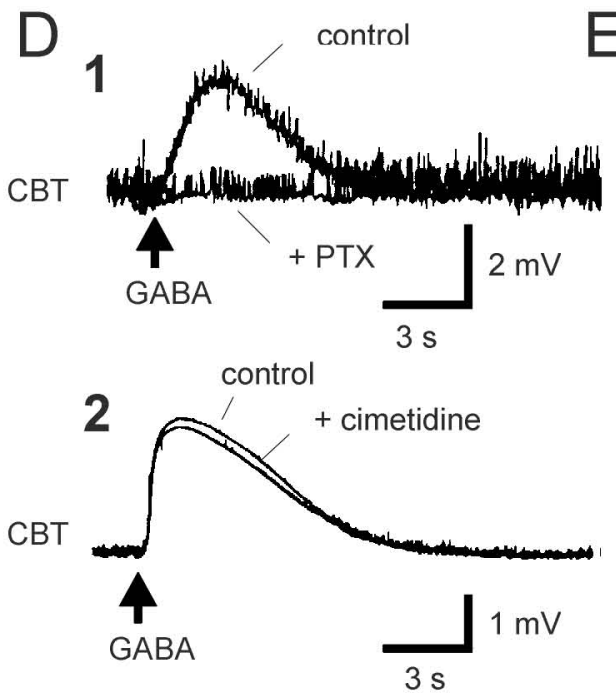

control
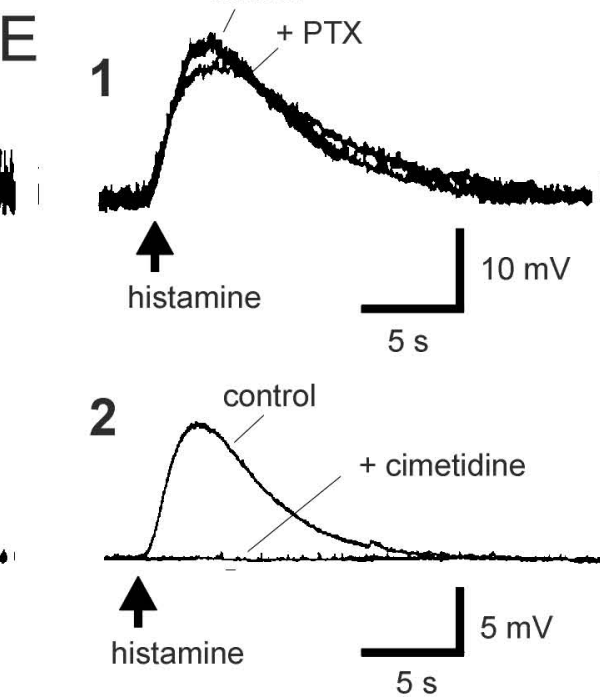


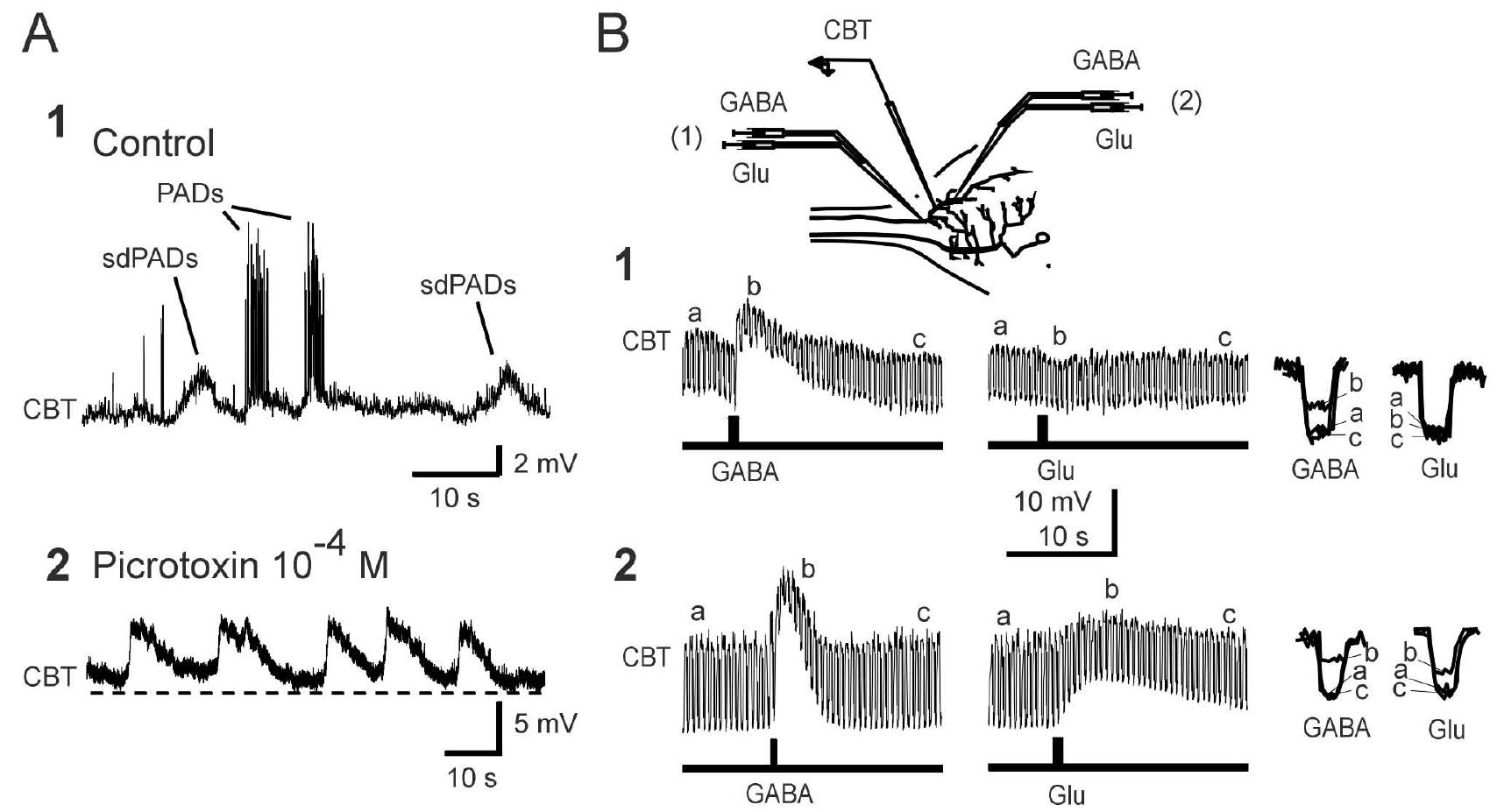


1

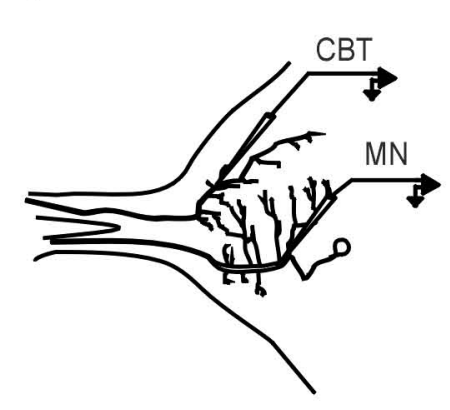

$\mathrm{B}_{1}$

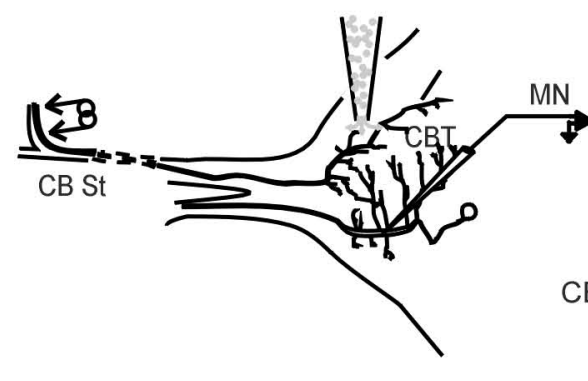

2

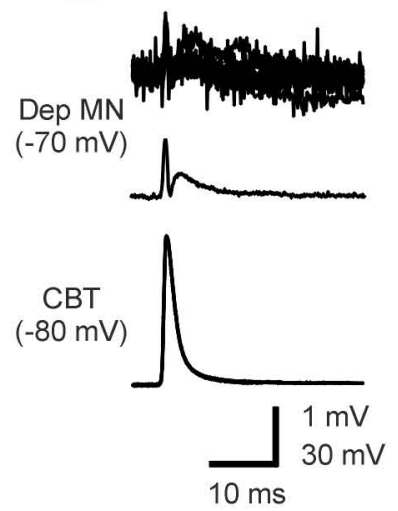

3 Postsynaptic induction

4

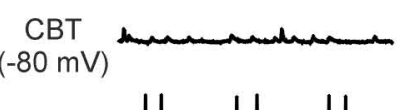

Dep MN (-69 mV)

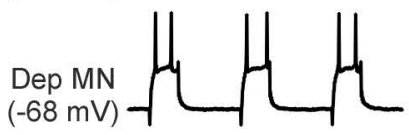

St $(+8 \mathrm{nA})$
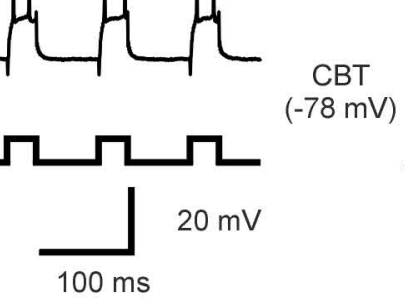

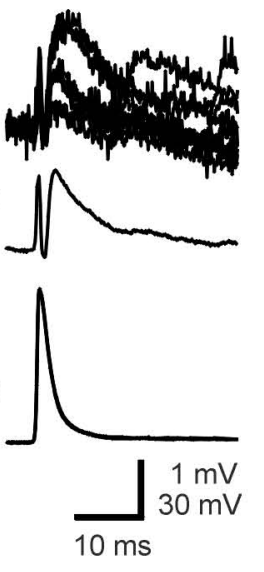

2

MN

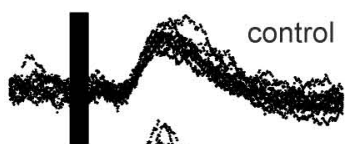

3

$15 \mathrm{~min}$

MN

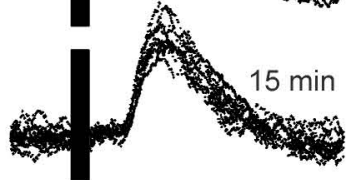

CB St

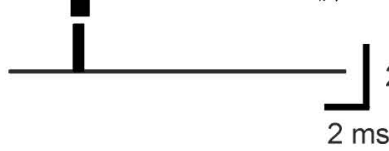

$2 \mathrm{mV}$

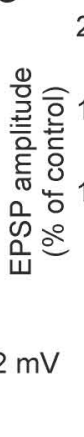

Glu injection control (Glu)

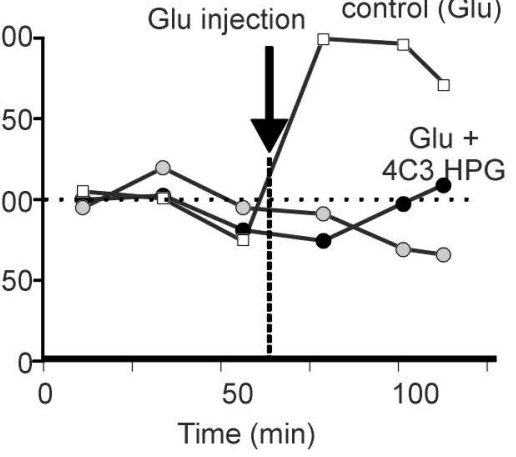

